Research Article

\title{
Zinc Metal at a New ZnO Nanoparticles Modified Carbon Paste Electrode: A Cyclic Voltammetric Study
}

\author{
Emad Salaam Abood ${ }^{\smile}$, Amer Mousa Jouda, Muthana Saleh Mashkoor \\ Department of Chemistry, Faculty of Science, University of Kufa, 54001 AnNajaf, Iraq. \\ Corresponding authors. E-mail: amadiraq45@gmail.com
}

Received: Apr. 7, 2017; Accepted: May 15, 2018; Published: May 23, 2018.

Citation: Emad Salaam Abood, Amer Mousa Jouda, and Muthana Saleh Mashkoor, Zinc Metal at a New ZnO Nanoparticle Modified Carbon Paste Electrode: A Cyclic Voltammetric Study. Nano Biomed. Eng., 20I8, I0(2): I49-I55.

DOI: 10.5101/nbe.v10i2.p149-155.

\begin{abstract}
A new carbon paste electrode modified with $\mathrm{ZnO}$ nanoparticles was prepared and used to study the electro oxidation of zinc ions in solution by cyclic voltammetry (CV) method. The modified electrode displayed strong resolving function for the overlapping voltammetric response of zinc into one welldefined peak. The potential difference between Epa and Epc was $>200 \mathrm{mV}$, the range of which referred to the quasi-reversible mechanism. The kinetic of electrode was studied in the range of temperature $15-30{ }^{\circ} \mathrm{C}$. The data of voltamograms showed the negative shift increased with increase of temperature, the result of which referred to the diffusion electron transfer in redox process of zinc oxidation. Diffusion coffining was calculated from Sevcik-Randles equation and thus equaled to $1.01 \times 10^{-7}$. The rate constant was equal to $5.2 \times 10^{-8}$ and $3.3 \times 10^{-8}$ for oxidation and redaction respectively. And the peak current of zinc increased linearly with its concentration in the range of 2.0$20.0 \mathrm{ppm}$.
\end{abstract}

Keywords: Cyclic voltammetry; Electrode; ZnO nanoparticales; Hydrothermal method

\section{Introduction}

Drug analysis plays important roles in drug quality control, and has great impact on public health. Therefore, a simple, sensitive and accurate method for the determination of active ingredient is very important [1].

Zinc is a nutrient that people need to stay healthy [2]. Zinc is found in cells throughout the body; it helps the immune system fight off invading bacteria and viruses; however, the change in the concentration may result in many diseases [3]. Thus, a quantitative determination of zinc concentration is significant for developing immune physiological and pharmacological research and life sciences. There are some methods applied for the determination of zinc, such as flow injection [4], fluorimetry [5] and spectrophotometry methods [6]. As an electroactive device, it can also be studied via electrochemical techniques. Some reports showed the electrochemical response of zinc on zinc ion electrode [7-8].

The electro chemical methods using chemically modified electrode have been widely used in sensitive and selective analytical methods for the detection of the trace amounts of biologically important compounds [9-11].

Electrode surface can be modified with metal nanoparticles and such surfaces have found numerous 
applications in the field of bio electrochemistry, particularly in biosensors. It has also been observed that nanoparticles can act as conduction centers facilitating the transfer of electrons. In addition, they provide large catalytic surface area. Many kinds of nanoparticles, including metal nanoparticles, oxide nanoparticles, semiconductor nanoparticles and even composite nanoparticles have been widely used in electrochemical sensors and bio sensors [12]. Zinc is electro active component that can be determined electrochemically [13]; however, it is very difficult to distinguish its response signals at bare electrodes because of their similar potential and interference from each other. Therefore, it is very important to develop a modified electrode to resolve the voltammetric response from each other. To the best of our knowledge, no study has been reported so far on the simultaneous determination of zinc by using carbon paste electrode modified with $\mathrm{ZnO}$ nanoparticles. In this research, we report the preparation and application of a carbon paste electrode modified with $\mathrm{ZnO}$ nanoparticles for determination of zinc ion without any additional modification such as addition of electron transfer mediator or specific reagent for the first time.

\section{Experimental \\ Apparatus and chemicals}

The electrochemical measurements were performed with an Auto Lab Potentiostat (DigiIvy 2113 Texas, USA) controlled by the General Purpose Electrochemical System Software. The ZnO nanoparticle carbon paste electrode was used as the working electrode. A calomel electrode and a platinum $(\mathrm{Pt})$ wire were employed as the reference electrode and counter electrode, respectively, and all potentials were reported with respect to the former. A Metrohm $\mathrm{pH} /$ ion meter was used for $\mathrm{pH}$ measurement.

All solutions were freshly prepared with doublydistilled water (conductivity of water was $0.055 \mu \mathrm{S} /$ $\mathrm{cm})$. All reagents were of analytical grade from Merck; graphite powder and paraffin oil both from Merck were used as received. High dilution of acids and bases was in the $\mathrm{pH}$ range of 2.0-8.0. All solution were deoxygenated with pure nitrogen gas for about $20 \mathrm{~min}$ prior to each electrochemical experiment.

\section{Preparation of ZnO nanoparticle by hydro- thermal method}

$\mathrm{ZnO}$ nanoparticles were synthesized by hydrothermal method. Typically, $13 \mathrm{~g}$ of $\mathrm{ZnCl}_{2}$ was dissolved in $300 \mathrm{~mL}$ of distilled water, and then a solution containing $8 \mathrm{~g}$ of $\mathrm{NaOH}$ was slowly added with stirring. After $8 \mathrm{~h}$, a white precipitate was obtained. The resulting precipitate was washed with distilled water and dissolved again in water to get solution, which was mixed with $50 \mathrm{~mL}$ of polyvinylpyrrolidone (PVP) (13 g of PVP dissolved in water) solution during a continuous stirring to get a homogeneous solution. The homogeneous solution was transferred into autoclave and heated at $160{ }^{\circ} \mathrm{C}$ for $8 \mathrm{~h}$. Then $\mathrm{ZnO}$ powder was obtained and dried at 100 ${ }^{\circ} \mathrm{C}$ after it had been washed with distilled water. TEM INSPECT S50, was used to determine the morphology of the synthesized $\mathrm{ZnO}$ sample. The morphology of the prepared $\mathrm{ZnO}$ was studied by transmission electron microscopy (TEM) (Fig. 1). The TEM image showed the agglomerated $\mathrm{ZnO}$ particles had an average size equal to $200 \mathrm{~nm}$ [15].

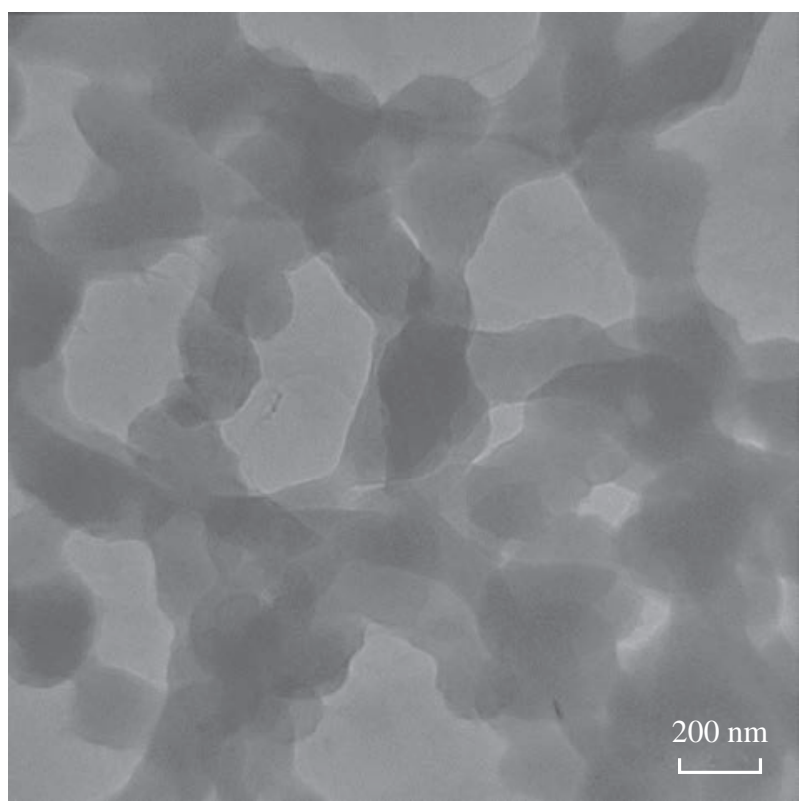

Fig. 1 TEM image of $\mathrm{ZnO}$ nanoparticles.

\section{Preparation of the electrode}

The $\mathrm{ZnO}$ modified carbon paste electrodes were prepared by mixing $0.1 \mathrm{~g}$ of $\mathrm{ZnO}$ nanoparticles, $0.9 \mathrm{~g}$ of graphite powder and $0.7 \mathrm{~mL}$ of paraffin oil with a mortar and pestle until a uniform paste was obtained. The paste was packed into the end of a glass tube (cross-section area $0.44 \mathrm{~mm}^{2}$ and length $10 \mathrm{~cm}$ ). The electrical contact was provided by inserting a copper wire into the carbon paste. Prior to the experiment, the surface of the carbon paste was polished with fine paper. The unmodified carbon paste electrode was prepared in the same way without adding $\mathrm{ZnO}$ nanoparticles to the paste. 


\section{Result and Discussion Cyclic voltammetry study of zinc}

Fig. 2 depicts the cyclic voltammetric response for the electrochemical oxidation-reduction of $0.1 \mathrm{~mol}$ $\mathrm{ZnSO}_{4}$ at $\mathrm{ZnO}$ nanoparticle carbon paste electrode. The anodic peak potential for the oxidation of $\mathrm{Zn}^{+2}$ and the reduction peak were about $-1.261 \mathrm{~V}$ and $-0.920 \mathrm{~V}$, respectively. While no response was observed on the carbon paste electrode (Fig. 2(b)). The result clearly indicated that the combination of graphite powder with $\mathrm{ZnO}$ nanoparticle improved zinc oxidation signal.

The effect of scan rate on the electro-oxidation of zinc at the $\mathrm{ZnO}$ nanoparticle carbon paste electrode was investigated by cyclic voltammetry (CV) (Fig. 3). A plot of peak current (Ip) versus the square root of scan rate $\left(\mathrm{V}^{1 / 2}\right)$ in the range of $0.1-5 \mathrm{~V} / \mathrm{s}$ was linear. This suggested that, at sufficient overpotential, the process was diffusion rather than surface control [14].

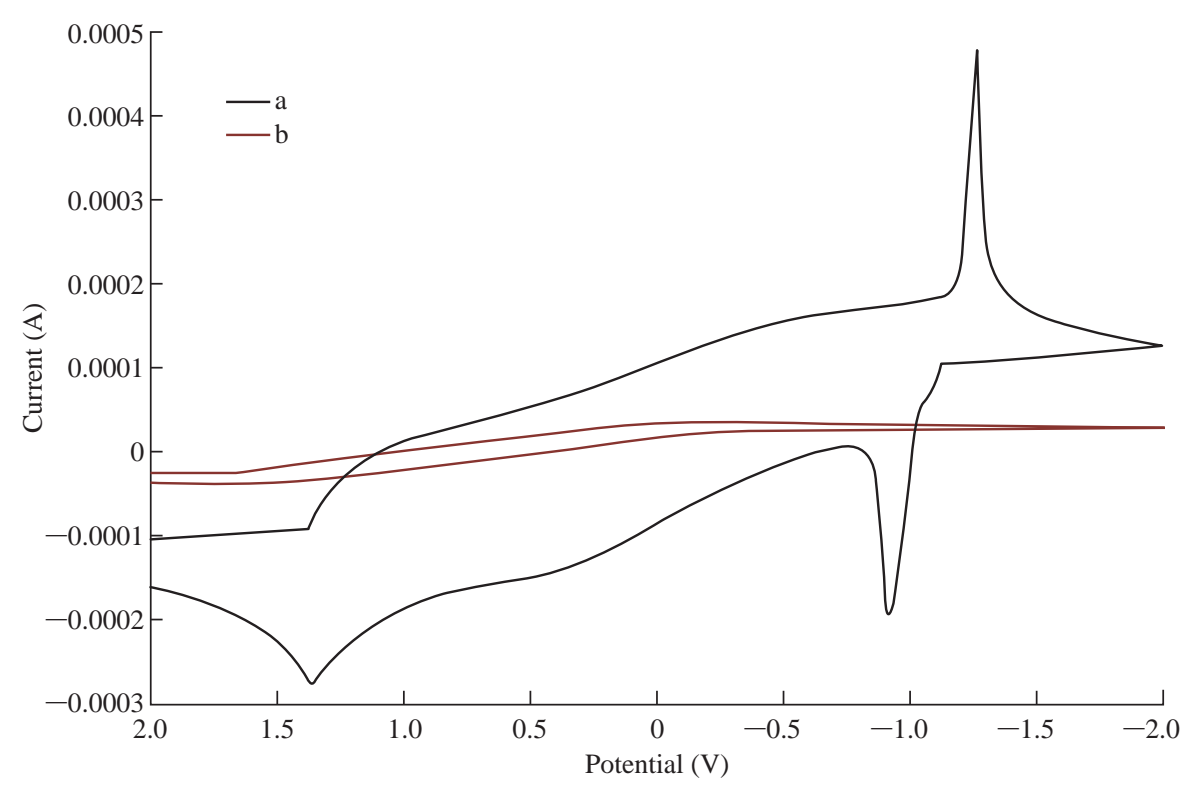

Fig. 2 Cyclic voltammogram of (a) $\mathrm{ZnO}$ nanoparticle carbon paste electrode and (b) carbon passed electrode in $0.1 \mathrm{~mol} \mathrm{ZnSO}_{4}$ solution at the scan rate of $0.1 \mathrm{~V} / \mathrm{s}$.

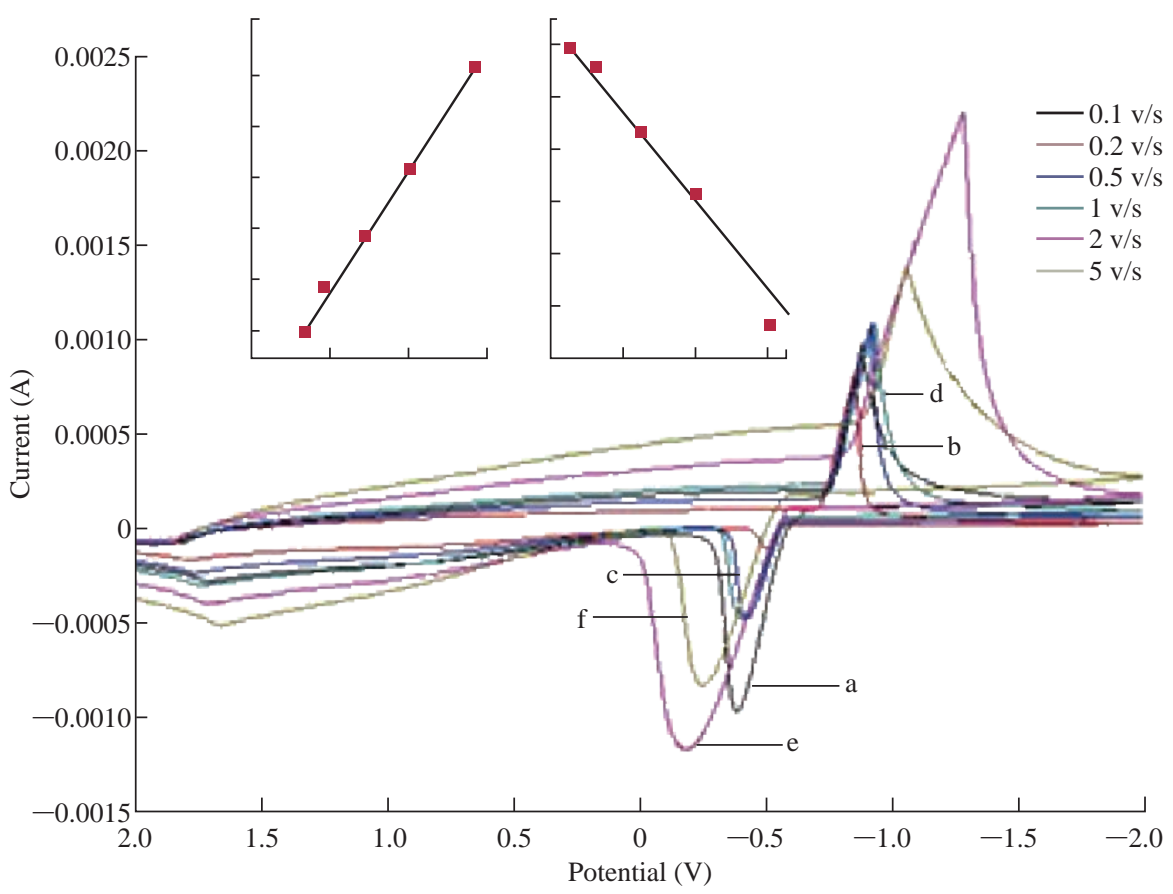

Fig. 3 Cyclic voltammogram of $\mathrm{ZnO}$ nanoparticle electrode in the presence of $0.1 \mathrm{~mol}$ of $\mathrm{ZnSO}_{4}$ solution at different scan rates of (a) 0.1 , (b) 0.2 , (c) 0.5 , (d) 1 , (c) 2 and (f) $5 \mathrm{~V} / \mathrm{s}$, respectively. 


\section{Temperature dependence study on the electro- oxidation of $\mathrm{ZnO}$ nanoparticle electrode}

A study of the electro-oxidation on electrodes was carried out with $\mathrm{CV}$ in the temperature range from $15{ }^{\circ} \mathrm{C}$ to $30{ }^{\circ} \mathrm{C}$ with calomel electrode; the best condition of $18-25{ }^{\circ} \mathrm{C}$ was used for calomel electrode [15]. The variation of the cyclic voltammogram (j-E) curves allowed the determination of activation energy in a wide interval of potentials where characteristic oxidation peaks appeared. Stationary current intensity measurements allowed the determination of the activation energy in pure kinetic region conditions. Temperature dependence of the charge-transfer resistance and the rate were constantly associated with the surface coverage by a diffusion intermediate during the electro-oxidation process, which was evaluated and discussed, suggesting that a complex mechanism took place for the electro-oxidation free of strong interactions with the $\mathrm{ZnO}$ nanoparticle electrode surface [16].

Result referred to the working electrode tacked the clear signal with Nernst equation (Eq. (1)) at $15-30{ }^{\circ} \mathrm{C}$ [17]: $\ln \mathrm{D}=\ln \mathrm{D}_{\mathrm{o}}-(\mathrm{Ea} / \mathrm{RT})$,

where $\mathrm{D}$ is the diffusion coefficient, $\mathrm{T}$ is the temperature, and $\mathrm{K}$ is the kelvin.

From the slop between $\ln \mathrm{D}$ and 1/Tk shown in Fig. 4, the free energy was calculated and equal to Ea $=68.94 \mathrm{KJ} / \mathrm{mol}$. This result revealed the exothermic reaction accrued when potential was provided on the working electrode, by Equation (2) [18]:

$\Delta \mathrm{G}=-\mathrm{nFR}(\Delta \mathrm{Ep})$,

where $\Delta \mathrm{G}$ is the free energy, $\mathrm{F}$ is the Faraday constant, $\mathrm{R}$ is the gas constant, and Ep is the difference in potential.

The free Gibbs energy was determined as of 58.7 $\mathrm{KJ} / \mathrm{mol}$, which referred to the spontaneous reaction. From last result, the constant of reaction $\mathrm{Kp}$ was calculated by used Nicholson equation (Eq. (3)) [19]:

$\mathrm{K}=\mathrm{K}^{0} \exp (-\alpha \mathrm{F} / \mathrm{RT})\left(\mathrm{E}-\mathrm{E}_{\mathrm{o}}\right)$.

$1.43 \times 10^{-5} \mathrm{~V} / \mathrm{s}$ for the quasi-reversible reaction of cyclic voltammtry referred to the first order reaction. Table 1 shows the kinetic and thermodynamic parameter for the $\mathrm{ZnO}$ nanoparticle carbon paste electrode.

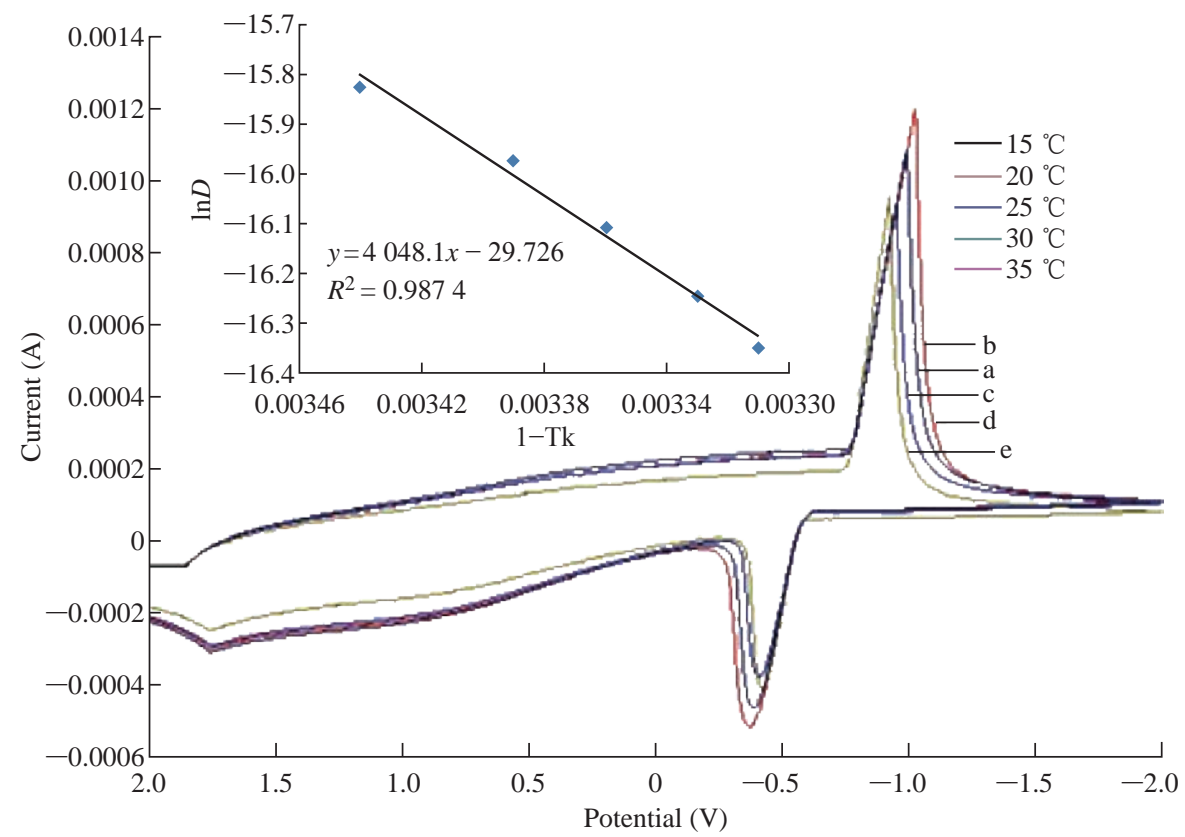

Fig. 4 Effect of temperature on the cyclic voltammogram for $\mathrm{ZnO}$ nano electrode as at (a) 15 , (b) 20 , (c) 25 , (d) 30 and (e) $35^{\circ} \mathrm{C}$, respectively. The $\mathrm{ln} \mathrm{D}-1 / \mathrm{Tk}$ plot for the calculation of Ea energy for $\mathrm{ZnO}$ nanoparticle electrode.

Table 1 Kinetic and thermodynamic parameters for $\mathrm{ZnO}$ nanoparticle carbon paste electrode

\begin{tabular}{|c|c|c|c|c|c|c|c|c|}
\hline Type of electrode & $\begin{array}{c}\Delta \mathrm{E} \\
\mathrm{KJ} / \mathrm{mol}\end{array}$ & $\begin{array}{c}\Delta \mathrm{H} \\
\mathrm{KJ} / \mathrm{mol}\end{array}$ & $\begin{array}{c}\Delta \mathrm{G} \\
\mathrm{KJ} / \mathrm{mol}\end{array}$ & $\begin{array}{l}\Delta \mathrm{S} \\
\mathrm{J} / \mathrm{ol}\end{array}$ & $\mathrm{K}_{\text {Oxd }}^{0} / \mathrm{s}$ & $\mathrm{K}_{\text {Red }}^{0} / \mathrm{s}$ & $\alpha$ & $\mathrm{D}^{0} 10^{-7}$ \\
\hline $\mathrm{ZnO}$ nanoelectrod & -37.904 & 32.4 & 8.7 & 70.8 & $5.2-10^{-8}$ & $3.2-10^{-8}$ & 0.5 & 1.01 \\
\hline
\end{tabular}

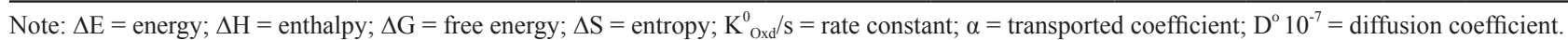


Calibration plots and determination of zinc in ZnO nanoparticle carbon paste electrode

Cyclic voltammetry was used to obtain the analytical features of the method such as linear ranges of the calibration plots and to detect the limits for $\mathrm{Zn}^{2+}$ [20].

Capability of separating the electrochemical response of $\mathrm{Zn}^{2+}$ by $\mathrm{ZnO}$ nanoparticle modified electrode was studied. Therefore, CV was used for the simultaneous determination of species based on its superior elimination of the capacitive background current. Analytical experiments were carried out by varying concentrations of $\mathrm{ZnSO}_{4}$ pure stock solution with $\mathrm{pH} 7.0$ by using $\mathrm{ZnO}$ nanoparticle electrode. Fig. 5 shows the calibration curve by $\mathrm{CV}$ obtained at 2-20 ppm, clearly revealing the response of the $\mathrm{ZnO}$ nanoparticle to $\mathrm{Zn}^{2+}$. Table 2 and 3 show the results for stock solution and real sample of zinc (Hasanl AZ VITAL, Germany) that contained vitamins A, C and E, folic acid, lutein, calcium, phosphorus, copper, iron and zinc with composition percentages of $40,10,20$,

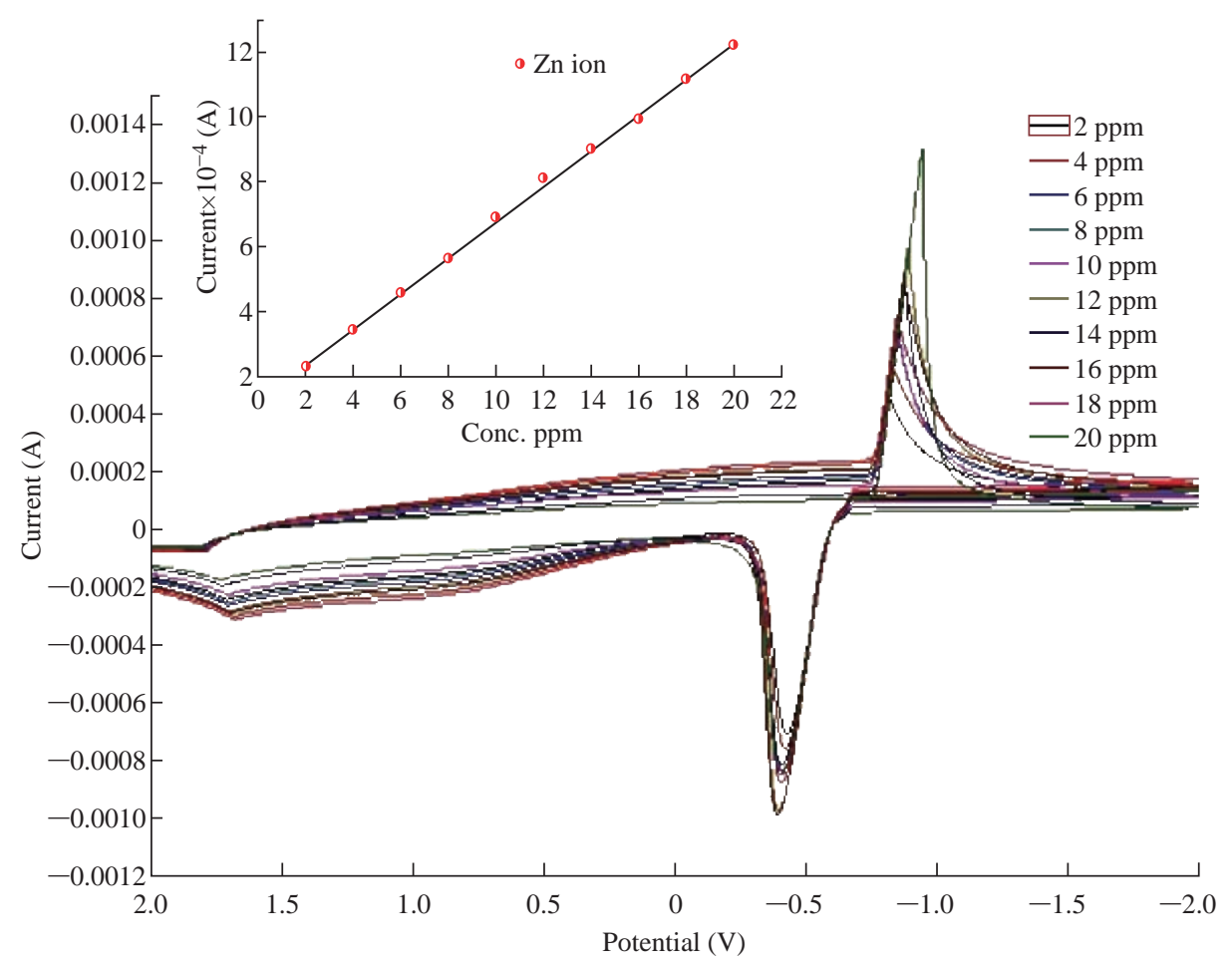

Fig. 5 Cyclic voltammograms and calibration curve by $\mathrm{ZnO}$ nanoparticle electrode for $\mathrm{ZnSO}_{4}$ stock solutions.

Table 2 Determination of real stock solution by deferent methods

\begin{tabular}{|c|c|c|c|c|c|}
\hline Method & Analyte (Zn/mg) & Linear range (ppm) & Founded (ppm) & RSD (\%) & Theoretical value (ppm) \\
\hline \multirow{4}{*}{ Cyclic voltammetry } & -- & $10^{-3}-10^{+3}$ & -- & -- & - \\
\hline & 5 & -- & 4.811 & 96.2 & 5 \\
\hline & 10 & -- & 9.641 & 96.4 & 10 \\
\hline & 15 & -- & 14.892 & 99.2 & 15 \\
\hline \multirow{4}{*}{ Colometry } & -- & $0.08-5$ & -- & -- & -- \\
\hline & 5 & -- & 4.625 & 92.5 & 5 \\
\hline & 10 & -- & 9.231 & 92.3 & 10 \\
\hline & 15 & -- & 14.612 & 97.4 & 15 \\
\hline \multirow{4}{*}{ Atomic radiation } & -- & $0.1-10^{+3}$ & -- & -- & -- \\
\hline & 5 & -- & 4.791 & 95.2 & 5 \\
\hline & 10 & -- & 9.611 & 96.1 & 10 \\
\hline & 15 & -- & 14.861 & $99.0 \%$ & 15 \\
\hline
\end{tabular}

Note: $\mathrm{RSD}=$ relative standard deviation. 
Table 3 Determination of real drug samples by deferent methods

\begin{tabular}{|c|c|c|c|c|c|}
\hline Method & Analyte (Zn/mg) & Linear range (ppm) & Founded (ppm) & RSD (\%) & Theoretical value (ppm) \\
\hline \multirow{4}{*}{ Cyclic voltammetry } & -- & $10^{-3}-10^{+3}$ & -- & -- & -- \\
\hline & 5 & -- & 3.912 & 78.2 & 5 \\
\hline & 10 & -- & 8.101 & 81.0 & 10 \\
\hline & 15 & -- & 12.301 & 82.0 & 15 \\
\hline \multirow{4}{*}{ Colometry } & -- & $0.8-50$ & -- & -- & -- \\
\hline & 5 & -- & 3.111 & 62.2 & 5 \\
\hline & 10 & -- & 7.315 & 73.1 & 10 \\
\hline & 15 & -- & 11.012 & 73.4 & 15 \\
\hline \multirow{4}{*}{ Atomic radiation } & -- & $0.1-10^{+3}$ & -- & -- & -- \\
\hline & 5 & -- & 3.900 & 78.0 & 5 \\
\hline & 10 & -- & 8.011 & 80.1 & 10 \\
\hline & 15 & -- & 12.021 & 80.1 & 15 \\
\hline
\end{tabular}

$10,5,5,5$ and 5\%, respectively. Equation (4) was used to prepare the measurement solutions:

$\mathrm{w} . \mathrm{t}=(\mathrm{ppm} \times \mathrm{M}$. wt of $\mathrm{Zn} / \mathrm{M}$.wt of drug $) /\left(10^{-6} \times \mathrm{V}\right)$.

All results pointed out that $\mathrm{ZnO}$ electrode was more sensitive than colorimetric and atomic analyzer for determination of trace amount in drug component.

\section{Conclusions}

Nano zinc oxide is a highly sensitive and selective vehicle that senses the small changes in the current passing through its solution when it becomes an electrode. Therefore, it was used to prepare the electrode and to study its physical and chemical properties. It was applied to measuring the small concentrations of some drugs containing zinc. The results were highly accurate in standard solutions and in real samples when compared to common methods such as atomic analysis and colorimetric method.

\section{Conflict of Interests}

The authors declare that no competing interest exists.

\section{References}

[1] Y. Liu, Z. Liu, and Y. Shi, Sensitive determination of epinephrine in pharmaceutical preparation by flow injection coupled with chemiluminescence detection and mechanism study. Luminescence: The Journal of Biological and Chemical Luminescence, 2011, 26(1): 5964.
[2] G. Bannach, P. Cervini, É.T.G. Cavalheiro, Using thermal and spectroscopic data to investigate the thermal behavior of epinephrine. Thermochimica Acta, 2010, 499: 123-127.

[3] M. Scott, M. Nakagawa, and A.B. Moscicki, CellMediated Immune Response to Human Papillomavirus Infection. Clin Diagn lab Immunal, 2001, 8: 209-220.

[4] J.X. Du, L.H. Shen and J. R. Lu, Cetyltrime thylammonium bromide-enhanced chemiluminescene determination of uric acid using a luminal-hexacyano ferrate (III) system. The Japan Society for Analytical Chemistry, 2003, 21: 183.

[5] F.N. Chen, Y.X. Zhang, and Z.J. Zhang, Simultaneous determination of epinephrine, noradrenaline and dopamine in human serum samples by high performance liquid chromatography with chemiluminescence detection. Chinese Journal of Chemistry, 2007, 25: 942-946.

[6] M.H. Sorouraddin, J.L. Manzoori., E. Kargarzadeh, et al., Electrochemical application to biology. Electrochemical Society, 2009, 08534-2839.

[7] Z. Lin, X. Wu, X. Lin, et al., End-column chemiluminescence detection for pressurized capillary electrochromatographic analysis of norepinephrine and epinephrine. Journal of Chromatography A, 2007, 1170(12): $118-121$.

[8] G. Bannach, P. Cervini, É.T.G. Cavalheiro, et al., Using thermal and spectroscopic data to investigate the thermal behavior of epinephrine. Thermochimica Acta, 2010, 499(1-2): 123-127.

[9] P. Xie, X. Chen, F. Wang, et al., Electrochemical behaviors of adrenaline at acetylene black electrode in the presence of sodium dodecyl sulfate. Colloids and Surfaces B: Biointerfaces, 2006, 48, 17-23.

[10] X. Chen, J. Zhao, G. Zhao, et al., A review on the synthesis of $\mathrm{TiO}_{2}$ nanoparticles by solution route. Central European Journal of Chemistry, 2012, 54: 279-294.

[11] P. Pradhan, R.J. Mascarenhas, T. Thomas, et al., Electropolymerization of bromothymol blue on carbon paste electrode bulk modified with oxidized multiwall carbon nanotubes and its application in amperometric sensing of epinephrine in pharmaceutical and biological samples. Journal of Electroanalytical Chemistry, 2014, 732: 30-37.

[12] C. Hu, S. Hu, H. Yi, et al., Functionalized multiwalled carbon nanotubes through in situ electropolymerization of brilliant cresyl blue for determination of epinephrine. Electroanalysis, 2010, 20: 1143.

[13] H. Nakazawa, Y. Ishii, M. Iijima, et al., Determination 
of nitrotyrosine and tyrosine by high-performance liquid chromatography with tandem mass spectrometry and immunohistochemical analysis in livers of mice administered acetaminophen. Journal pharma Biomed, 2015, 41: 1325.

[14] J. Hanaee, Carbon film resistor electrode for amperometric determination of acetaminophen in pharmaceutical formulations. Journal of Pharmaceutical and Biomedical, 2007, 43: 1622-1627.

[15] O. Fasakin, M.A. Eleruja, O.O. Akinwunmi, et al., Synthesis and characterization of metal organic chemical vapour deposited copper titanium oxide $(\mathrm{Cu}-\mathrm{Ti}-\mathrm{O})$ thin films from single solid source precursors. Journal of Modern Physics, 2013, 4: 41158.

[16] A.E. Suliman, Y. Tang, and L. Xu, Preparation of ZnO nanoparticles and nanosheets and their application to dyesensitized solar cells. Solar Energy Materials and Solar Cells, 2007, 91: 1658-1662.

[17] R. Wahab, S.G. Ansari, Y.S. Kim, et al., Low temperature solution synthesis and characterization of $\mathrm{ZnO}$ nanoflowers. Materials Research Bulletin, 2007, 42: 1640-
1648.

[18] M. Cao, Y. Wang, Y. Qi, et al., Synthesis and characterization of $\mathrm{MgF}_{2}$ and $\mathrm{KMgF}_{3}$ nanorods. Journal of Solid State Chemistry, 2004, 177: 2205-2207.

[19] A.A.A. Darwish, M. Rashad, A.E. Bekheet, et al., Linear and nonlinear optical properties of $\mathrm{GeSe}_{2}-\mathrm{xSnx}$ thin films for optoelectronic applications. Journal of Alloys and Compounds, 2017, 709: 640-645.

[20] R.L. Penn, J.F. Banfield, ZnO-based dye-sensitized solar cells. Journal of Alloys and Compounds, 2017, 91, 16851689.

Copyright $\subset$ Emad Salaam Abood, Amer Mousa Jouda, and Muthana Saleh Mashkoor. This is an open-access article distributed under the terms of the Creative Commons Attribution License, which permits unrestricted use, distribution, and reproduction in any medium, provided the original author and source are credited. 